\title{
Practice challenges in patient safety
}

\author{
Desafios da prática na segurança do paciente \\ Desafíos de la práctica en la seguridad del paciente
}

ORIGINAL ARTICLE

Andréia Guerra Siman'

ORCID: 0000-0001-7990-9273

Luciene Muniz Braga'

ORCID: 0000-0002-2297-395X

Marilane de Oliveira Fani Amaro' ORCID: 0000-0002-9495-0861

Maria José Menezes Brito"

ORCID: 0000-0001-9183-1982

'Universidade Federal de Viçosa. Viçosa, Minas Gerais, Brazil. "Universidade Federal de Minas Gerais. Belo Horizonte, Minas Gerais, Brazil.

How to cite this article: Siman AG, Braga LM, Amaro MOF, Brito MJM. Practice challenges in patient safety. Rev Bras Enferm. 2019;72(6):1504-11. doi: http://dx.doi.org/10.1590/0034-7167-2018-0441

Corresponding Author:

Andréia Guerra Siman E-mail:ago.80@hotmail.com

Submission: 06-07-2018

Approval: 03-02-2019

\begin{abstract}
Objective: to understand the professional practice challenges in reaching the goals and objectives of the National Patient Safety Program (Programa Nacional de Segurança do Paciente). Method: qualitative case study, based on the Comprehensive Sociology, carried out with 31 professionals from the Patient Safety Center (Núcleo de Segurança do Paciente) and the nursing team, working in a teaching hospital. Data collection took place between May and December 2015 through interviews, observation and documentary analysis. The analysis proceeded according to the prerogatives of the Content Analysis. Results: three categories emerged: the prescribed reality; material resources and their impact on care; and human resources related to the reality. Final considerations: challenges to safe professional practice are caused by inadequate physical structure, insufficient physical and human resources, but mainly invade the transition from the prescriptive reality scope. Descriptors: Patient Safety; Quality of Health Care; Professional Practice; Nursing; Hospitals.
\end{abstract}

\section{RESUMO}

Objetivo: compreender os desafios da prática profissional para o alcance das metas e objetivos do Programa Nacional de Segurança do Paciente. Método: estudo de caso qualitativo, fundamentado na Sociologia Compreensiva, realizado com 31 profissionais do Núcleo de Segurança do Paciente e da equipe de enfermagem, que trabalhavam em um hospital de ensino. A coleta de dados ocorreu entre maio e dezembro de 2015 por meio de entrevistas, observação e análise documental. A análise procedeu conforme as prerrogativas da Análise de Conteúdo. Resultados: emergiram três categorias, sendo elas: A realidade prescrita; Os recursos materiais e seus impactos no cuidado; e $A$ realidade relacionada aos recursos humanos. Considerações finais: os desafios para a prática profissional segura perpassam pela estrutura física inadequada, insuficiência de recursos materiais e humanos, mas, principalmente, invadem a transição das mudanças no âmbito prescritivo para o real.

Descritores: Segurança do Paciente; Qualidade da Assistência à Saúde; Prática Profissional; Enfermagem; Hospitais.

\section{RESUMEN}

Objetivo: comprender los desafíos de la práctica profesional para el logro de las metas y objetivos del Programa Nacional de Seguridad del Paciente. Método: estudio de caso cualitativo, fundamentado en la Sociología Comprensiva, realizado con 31 profesionales del Núcleo de Seguridad del Paciente y del equipo de enfermería, que trabajaban en un hospital de enseñanza. La recolección de datos ocurrió entre mayo y diciembre 2015 a través de entrevistas, observación y análisis documental. El análisis procedió conforme a las prerrogativas del Análisis de Contenido. Resultados: surgieron tres categorías, siendo ellas la realidad prescrita; los recursos materiales y sus impactos en el cuidado; y la realidad relacionada con los recursos humanos. Consideraciones finales: los desafíos para la práctica profesional segura atraviesan la estructura física inadecuada y la insuficiencia de recursos materiales y humanos, pero principalmente invaden la transición de los cambios en el ámbito prescriptivo para el real.

Descriptores: Seguridad del Paciente; Calidad de la Asistencia Sanitaria; Práctica Profesional; Enfermería; Hospitales. 


\section{INTRODUCTION}

Evaluation of service quality, improved Patient Safety and Patient Safety culture are structural components to improve safe practice in health services ${ }^{(1-2)}$. Patient Safety is to minimize the risk of harm to the patient. It is an ongoing process involving educational activities, systematized actions to detect, analyze Adverse Events (AE) and risk situations ${ }^{(3)}$.

There are landmark initiatives such as the publication of the report on errors related to health care: "To err is human: building a safer health system", stating that as many as 98,000 deaths per year in the United States of America (USA) could be due to medical errors ${ }^{(4)}$, which generated a warning to health institutions. In this sense, the error is the failure, action that do not occur as planned or incorrect application of the plan; and the AE are any damages or injury caused to the patient as a result of the intervention of the health team ${ }^{(5)}$.

In this perspective, in recent years, studies have shown that the practices of healthcare professionals have been marked by high rates of $A E$ in surgical procedures, administration of medications, hospital-acquired infections, injuries to patients, hospital care system failures, permanent damage, and fatalities. Inappropriate, unsafe and negligent practices affect between $3 \%$ and $16 \%$ of hospitalized patients in developed countries ${ }^{(6-8)}$. Therefore, maintaining a caring process based on the patient's real need, with a safe environment and assistance, has been configured as a major challenge.

In 2013, in Brazil, the National Patient Safety Program (PNSP Programa Nacional de Segurança do Paciente) was instituted and the Collegiate Board Resolution 36 (RDC - Resolução da Diretoria Colegiada 36/2013), which instituted actions to promote Patient Safety and improve quality in health services ${ }^{(3)}$.

It is a fact that structural and process aspects affect Patient Safety ${ }^{(9)}$. However, when conducting studies in organizations, it is necessary to consider the human element, the context and the organization of work. The problem arises when one looks at the questions between the prescribed and the real. The prescription is not the real, because the reality of the context of health institutions is complex ${ }^{(10)}$. The prescribed component is an abstract, formal and static component; and the real component is concrete, true, informal and dynamic. The real, in organizations, is basically a technical organization that permeates human interactions and modifies it, gives it a concrete form ${ }^{(10)}$. Thus, the distance between the prescribed and the real presents a privileged object for the analysis of practices, values, beliefs that represent confrontations between the way of managing the work and the ways of doing and thinking of the workers.

Therefore, in order to understand people's real behavior, one must understand the real context. It is worth mentioning that the work must be organized in such a way as to impact the quality of the assistance beyond the prescribed practices, that is, it must move from the political to the care and operational scope.

In the present study, it is assumed that there is a distance between the prescribed dimension (protocols, reports, records, indicators and action plans of the Patient Safety Center (NSP - Núcleo de Segurança do Paciente) in the planning of Patient Safety practices in the hospital context and the reality of professional practices. This fact reinforces the need to understand the challenges to professional practice in the real context, as they involve a complex and multidisciplinary process that requires the planning of common goals by professionals to provide a safe and quality care.

Therefore, in this study, working with the concept of professional practice in the broadest sense was chosen as social practices within the praxeological perspective. It is an approach that aims to group management analysis, institutional, organizational and behavioral levels, allowing the intersections within human action $^{\left({ }^{111}\right)}$. Adopting the perspective of social practice is to consider health workers as social subjects in a process of relationship, in which they produce health practices collectively and directed to specific ends, shared by all members of a community ${ }^{(12)}$.

This study is justified, considering the importance of incorporating safe practices in Health and that the problem affects several patients, in addition to the shortage of national studies on the subject, mainly to portray the limitations of public health services. With the considerations presented, it is intended to answer the following guiding questions: how have the practices of health professionals occurred in the implementation of Patient Safety? What challenges do you face in this context?

\section{OBJECTIVE}

To understand the challenges of professional practice to achieve the goals and objectives of the PNSP.

\section{METHOD}

\section{Ethical aspects}

This study was approved by the Research Ethics Committee Involving Human Beings of the Universidade Federal de Viçosa MG, Brazil. Opinion 1,072,502.

\section{Theoretical-methodological framework}

This is a qualitative research delineated by the research strategy of the case study and based on Comprehensive Sociology. The case study aims to analyze a social unit, seeking to answer "how" and "why" phenomena occur. For this reason, it is ideal for organizational studies that seek to portray reality in a complete and profound way ${ }^{(13)}$. The heart of Comprehensive Sociology is the conception of the actions and relations of individuals in a social context. It is the recognition that these relations between individuals have causal importance, since relations guide action $s^{(14)}$. In this sense, the Comprehensive Sociology considers the role of the individual and his action in the construction of reality.

\section{Type of study}

This is a case study based on the Comprehensive Sociology.

\section{Methodological procedures}

\section{Study setting}

The study setting was a teaching hospital located in the Zona da Mata (The Zona da Mata ("forest area") is the narrow coastal plain between the Atlantic Ocean and the dry" agreste" and "sertão" 
regions in the northeastern Brazilian states of Maranhão, Piauí, Rio Grande do Norte, Paraíba, Pernambuco, Alagoas, Sergipe and Bahia) of Minas Gerais, which develops quality improvement strategies and has a risk management committee. It has 116 beds and, at the time of the study, had six adult hospitalization units and an average of 5,232 patients per day each month. Since 2012, it has been accredited to the Brazilian Network of Sentinel Hospitals. In 2013, the NSP was composed of the members of the risk management committee, which started notifying $A E$.

\section{Data source}

The research participants were nurses and nursing technicians working in hospitalization units, and professionals who are members of the NSP. All NSP nurses and members worked 40 hours a week, except for the nurse working at Hospital Infection/Quality Control Committee (CCIH - Comissão de Controle de Infecção Hopitalar/Qualidade), with a workload of 30 hours/week. Nursing technicians complied with a 12/36 hour scale.

The inclusion criteria for the nursing team were to work at hospitalization units, medical and surgical clinic; to have at least one year of work; and NSP professionals to be effective and active members. Participants who were removed from office for some reason during the collection period were excluded and those who refused to formally participate in the study.

The choice of NSP professionals has occurred because it is understood that they manage and prescribe actions to achieve Patient Safety. With respect to the nursing staff of hospitalization units, the results of a survey in which the ward was chosen as the place with the highest frequency of $A E(56.9 \%)$ was based on the nursing staff of hospitalization units ${ }^{(6)}$.

The NSP was composed of 15 members. Two were on medical leave and one refused to participate, totaling 12 participants. In the nursing team, all seven nurses were interviewed. Secondary data were obtained through documentary research. Thus, documents relating to quality management were used; reports, protocols, indicators, records, and action plan.

\section{Collection and organization of data}

Data collection was performed through triangulation of data, with primary and secondary data, between May and December 2015. Primary data were collected through interviews with semi-structured script and non-participant observation with recording in field diary.

In the interviews, data saturation criterion ${ }^{(13)}$ was applied only to the group of nursing technicians. Thus, participants of the study were the nurses, 12 members of the NSP and 12 nursing technicians, according to the inclusion and exclusion criteria applied.

A pilot test was conducted with two health professionals, to evaluate the interview script, who were not included in the participants' list. The script covered aspects of knowledge in the area of Patient Safety, practices and actions taken by the team to achieve Patient Safety, difficulties and facilities to reach international goals of Patient Safety and the participation of the team in this process. The interviews were scheduled with each participant and conducted by the principal investigator, at the workplace, in a reserved room, lasting 10 to 100 minutes. All were recorded and transcribed in full, being coded with the acronym NSP (Patient Safety Center - Núcleo de Segurança do Paciente); N (Nurse); NT (nursing technician) followed by interview number. Non-participant observation occurred in the hospitalization unit to better understand the professionals practice during the work process, with duration of 72 hours and a mean of 12 hours in each hospitalization unit. It was observed aspects related to the behavior of the subjects of the organization, communication and work dynamics in the sectors visited, assistance, admission of patients by the nursing team, conversations, behaviors, expressions and other relevant issues.

\section{Data analysis}

For data analysis, Content Analysis ${ }^{(15)}$ was used, which consists of a set of communication analysis techniques, carried out around three chronological poles: the pre-analysis, the exploration of the material and results treatment. Firstly, in pre-analysis, all the material was organized and a quick reading was carried out, exhaustive readings, allowing the corpus constitution with appearing formulations based on the data content. Then, coding and categorization of the topics raised was carried out, whose systematic procedure allows to highlight the "registry units" (words/themes), constituting three categories. After categorization, contents were analyzed, with interpretation and data inferences, based on the literature. This led to the emergence of three categories: The prescribed reality; Material resources and their impact on care; and The reality related to human resources.

\section{RESULTS}

\section{The reality prescribed}

This category was elaborated, mainly, with the documentary analysis and the field observation. The institution, scenario of the study, from the risk management commission, founded the NSP in 2013; at the time, the forms of notification of technical complaints. In 2015, this same body extended the instrument and initiated the notifications of $\mathrm{AE}$.

The NSP was appointed by the administrative director. Participants included six nurses representing the (Surgical Block, Intensive Care Unit, Technical Manager, $\mathrm{CCIH}$, Sterilized Material Center and Blood Bank), a nursing infection control technician, a nutritionist, the reception coordinator (trained in home economics), the maintenance coordinator (trained in administration), the pharmacist (technical in charge of the pharmacy) and the operational support manager (trained in administration). There was no medical representative.

Representativeness of several sectors was an attempt to insert professionals from the entire institution; $83.33 \%$ were female, mostly nurses. Regarding the age group, the age of NSP members ranged from 26 to 50 years, with a mean of 38.33 years. Regarding the training time, there was a variation from 3 to 30 years, with an average of 10.3 years. All of them had coordination positions and did not know aspects of Patient Safety until they entered the hospital. After the appointment of the NSP, the members participated in a course on Patient Safety offered by the institution. 
Regarding protocols, the objective was to identify only those related to PNSP. Thus, the following were described: pressure injury; which gives; safe surgery; patient identification; hand hygiene; enteral and parenteral therapy; administration of blood components. Through the observation, it was verified that there was no protocol of medication administration with the justification of not having a clinical pharmacy. Moreover, it was observed that protocols were only available in the quality sector.

Regarding the Patient Safety Plan (PSP - Plano de Segurança do Paciente), according to the PNSP, mandatory for the NSP, it was observed that there were no actions and goals for the institution to achieve Patient Safety. The use of evaluation tools and strategies for the reduction of AE were not observed. It should be emphasized that the PSP was an instrument developed by the quality manager, without the participation of the other members, according to speeches:

I'll be very honest, if you had action plan I do not remember how it was performed. There are some protocols that I helped to do, but there is already a lot of time, it was injury prevention and I do not remember. (NSP9)

I've already seen a little bit about the internal regiment, but the action plan, I did not get to see it. (NSP10)

\section{Material resources and their impacts on care}

This category was compiled with data from the field diary and the questions on difficulties and facilities to reach the international goals of Patient Safety. It portrays the difficulties related to the infrastructure of the hospitalization units: lack of bed rails, lack of chairs and stretchers, absence of communication and signaling bells in the bed, inadequate beds and beds and poor physical resources. These elements were cited by health professionals and characterized the conditions inappropriate for work performance:

Rails do not go up. There's the bathroom, you could have some things to hold for the elderly, you know? There is not. They could have more things like that. (NT23)

Chairs that are not adapted, bath chair has no backrest. Today my patient almost fell out of the bathroom because the chair had no backrest. There is only one piece of iron there and she complained of pain because she was on a bad chair. (NT18)

This month they put an old lady in a bed that did not have any of the rails and she was a bit confused. The escort was not in the moment and she ended up falling. (N14)

The doorbell! There is not! You have to call, there's no sign of light on the bed door [...] The bed rail is not 100\%. Then, put a little chair underneath, if you let go of the safe chair. When we take a patient to $x$-ray, sometimes there are chairs missing. We have difficulty finding a litter. (NT21)

The perceived conditions translate into the lack of investment in basic structural resources and quality, impacting on the practice of care. Professionals developed their practices in a setting of insecurity:
There is no vacuum in the beds. None of the beds have, have the laptop or suck patient in the compressed air, because that's what the institution has. (N1)

Yeah, there's a lot of infrastructure, poor quality material. (N30)

For example, material with safety device, syringe that secures the employee, could bring more benefits to the patient. Or more material, to have more quantity in the wings. (NSP2)

Oh, pressure device! There are times when we do not have a pressure device. Patient has to measure pressure all the time, there is a difficulty, and also blood glucose meter. (NT23)

Sometimes there is lack of equipment, lack of material for you to work on. (NT22)

In addition to the inadequate supply of materials, it was observed and confirmed by the statements that there was no preventive equipment maintenance:

Equipment risks. You take a cardioverter, for example, you have to have preventive maintenance and you do not have. Who guarantees that when the patient is going to get there it will work? That worries me. There is a risk of the bed breaking. Risk of infection because it is all rusty. (NSP5)

There are some headboards that are loose; there is a patient to let it leak down there. Everyone knows that the monitors have become scrap metal, which is 12 years of ICU and has never been maintained. It operates 24 hours a day, 365 days a year. One hour will be defective. And we warn you, this business stresses me, my hair falls and nobody pays my bill there at the dermatologist. (NSP9)

The speeches translate professionals who are not in agreement with the reality of the institution, with the working conditions and their consequences for the safety of the patient and the professionals themselves. Some occurrences, such as infusion pump failures, medication delivery valves altering the infusion, problems with mechanical ventilators and unsafe monitors, can be observed in the previous and confirmed statements below:

We once had equipment that did not control dripping because we do not have quality referral to buy material and this is lousy for us. It is a serious mistake that falls on us, because no one wants to know if they controlled drip or not. Closed equipment, the medication was closed, when welooked, it had spoiled everything up. We have already standardized a brand, but go and see if it is brand X. Glove, jelco, pump equipment, but have a lot of blue equipment for medication. What security is this that l am giving? Because the risk of making mistakes is too great. You get high noradrenaline there you stay there at the pump. I started using photosensitive equipment and it's expensive, it does not have conditions. I'm being silly here. You can see the level (NSP9)

Through the testimonies, it is possible to identify cases of serious $A E$ due to a lack of investment in medical devices and equipment, including in highly complex sectors, such as the Intensive Care Unit (ICU), hemodialysis and the Surgical Block (SB):

These my outlet facilities are old [...] there is no such total security. So there are some adverse events that happen. A monitor that 
turns off. An outlet that does not turn on. An apparatus that does not ascend, extensions that remain as bare. We have these problems. (NSP 12)

I ask them a lot not to trust the monitor because it does not ring the alarm. (NSP9)

For example, the hemodialysis machine stops during patient care and stops treatment and has not been reported. And the patient is harmed. (N1)

\section{The reality related to human resources}

This category presents the difficulties related to human resources. Reduced number of staff, work overload, stress, delays in wages, low pay and high turnover of professionals were highlighted, aspects that, from the view of participants, impact on safe practice. Quantitative deficit of the nursing team and physicians, for assistance that meets the safety requirements, was the most cited aspect of the participants:

I think Patient Safety is poor. By the professional staff. I have seen during the final sum of indicators that had falls, patient who had no pressure ulcer and after hospitalization or after being transferred from one sector to another and had pressure ulcer. There is insufficient staffing [nursing team]. (N1)

During field observation, it was possible to identify that nurses provided care in more than one hospitalization unit during the day shift, taking about thirty patients. At night shift, there was only one professional responsible for the entire hospital, except for prompt care and ICU. The speeches contribute with the observations:

At night we have a single nurse, for the whole hospital, then you imagine. He solves everything. For example, everything that happens we call him, being related to Nursing or not. So he stays the night because of everything. And there is one in the ICU, one in the ready service and another one for the rest, the wings. There's an urgency in Ward C and Ward D at the same time, and then? It gets hard. Night gets hard to work. (NSP2)

Absences and reduced human resources lead to an overload of work, which significantly influences Patient Safety:

We have here today, in relation to the assistance, a small number of personnel and can generate a fall of the bed. Sometimes we have three technicians to serve a unit with 30 beds, 30 occupied beds. (NSP6)

It is work overload [...] for the nurse. Everything at ward is the nurse. (NSP2)

The work day is very hard, which disturbs me more so that we can develop a nice job. (NT26)

Patients are getting into the hands of residents. They miss a lot, I've even seen venous Tylenol prescription. (NT23)

The lack of development and personal valorization, aspects characterized by the low salaries and the high turnover of the team, resulting in stressed professionals:
It is employee working stressed, poor and insufficient salary, having to work in various places. (N30)

[...] turnover that kills people and we get overwhelmed. (NSP12)

\section{DISCUSSION}

The first category reveals changes in the prescriptive scope of the organization, such as the creation of the NSP, the institution of AE notifications and elaboration of protocols, but difficulties in achieving them in the real scope. The strategic and articulating formation of the center ${ }^{(3)}$ justifies a composition involving professionals and managers from diverse sectors. In order to comply with the principle of systematic dissemination of the safety culture ${ }^{(2-3)}$, a doctor or medical residency representative in the NSP. However, there was no representation of the category. Evidence that participants were unaware of the guidelines for safe practices with a focus on quality of health care reinforces the realization that professional training in the area of health, encompassing aspects of Patient Safety in the curriculum, is still insipid in the national context ${ }^{(3)}$.

Data from the first category still depict the institution's actual safety protocols described, except drug administration, but not available to the team. The World Health Organization has chosen the Patient Safety protocols, all available for implantation, which are: patient identification, safe surgery, pressure ulcer prevention, hand hygiene practice in health services, prescription safety use and medication administration and fall prevention ${ }^{(3)}$. Protocols are tools to improve Patient Safety and should be systemic, managed, and empower teamwork ${ }^{(3)}$. In addition, results should be monitored using Patient Safety indicators ${ }^{(3,16)}$. This reality was not found in the institution under study, portraying the challenges of the care and management practice, in the achievement of the goals and objectives of the PNSP, both in the macro (institution) and microssocial (sectoral) context.

National guidelines also guide how to establish the PSP; a document that identifies risk situations and describes the strategies and actions defined by the health service for risk management, aiming at prevention and mitigation of incidents, from admission to discharge or death of the patient. Its elaboration must be collective, multidisciplinary, involving the largest number of units and their teams to facilitate their performance and understanding ${ }^{(3)}$. In order to do so, there is the challenge of involving people, improving interaction, and understanding the meaning and the contextual influences on professional practices, which are consistent with the real scope of organizations ${ }^{(10,14)}$. These findings portray that strategies are still needed to develop the safety culture in the institution. Considering the theoretical framework adopted, in developing this culture, it will influence the professional practices of the individual and the way he reacts and interprets a challenge.

The prescribed aspects are fundamental to start the work organization and to direct the practices of health professionals. However, keeping them only in the prescriptive scope is not enough. In other words, it is necessary to implement the actions described in the PSP in the institutional reality and use tools to assess the achievement of goals, improving communication, 
directing and transforming the practices of professionals in the real scope of the hospital organization. Thus, by investing in teamwork and their relationships, recognizing that these relationships are causally important, and that they can guide the practices and actions of individuals ${ }^{(14)}$, will achieve safer practices and consequently give meaning to this practice, starting from the assumption that the individual is moved by the sense that he attributes to the relations ${ }^{(14)}$.

Articulating with evidence from another study, the authors found that the implementation phase of Patient Safety strategies involves a slow process, with difficulties in developing a positive safety culture. In order to achieve the proposed goals and objectives, it is essential, in addition to the formation of the NSP; to develop a safety culture in the institution; to train and involve all professionals who provide direct or indirect assistance, especially nurses, because he is the leader of the nursing team, has a broad technical-scientific knowledge and provides care to patients most of the time ${ }^{(16-17)}$.

Second and third categories results revealed challenges faced by professionals, related to human and material resources, to provide safe assistance to patients and their relationship with avoidable $A E$, such as, for example, the fall of the patient from the bed and pressure injury. According to a Brazilian study ${ }^{(6)}$, these $A E$ accounted for about $25 \%$ of the avoidable $A E$, since they can be prevented when a continuous risk assessment through scales, by the nursing team; and preventive interventions based on the best evidence ${ }^{(6)}$. In addition, the absence of adequate nursing professional dimensioning generates nursing work overload, with an increase in the risk of $A E$, as evidenced in this study and in another ${ }^{(18)}$.

Insufficiency of material resources and their quality constitute a limitation to develop a safe practice, necessitating the overcoming of multifactorial difficulties. These findings are corroborated by other studies ${ }^{(18-20)}$ and reinforce the need for preventive equipment maintenance, and improvements in hospital management to control risks, maintain safety conditions, quantity and quality of material resources to prevent accidents and injuries ${ }^{(21)}$.

For an adequate infrastructure, with a view to Patient Safety, it can be inferred that there is a need for greater investment and better management in the hospitals agreed to the Brazilian Unified Health System (Sistema Único de Saúde). Political and organizational commitment is necessary, addressing the needs for accessibility, safety, quality and cost-effectiveness. An adequate physical structure and environment, medical equipment and other resources often support the clinical care provided and therefore must be used safely ${ }^{(21-22)}$.

Another challenge for a safe practice, identified in the present study, is related to human resources, which were related by participants with the number of nursing professionals, with work overload, with salary compensation and high turnover. Other studies confirm these findings and reveal the fragility of staffing and the need for a larger number of nursing professionals, especially at night, to provide safe and quality care ${ }^{(2,23)}$. Personnel sizing is directly related to the quality of care when analyzing the safety culture and quality indicators, with an increase in infection rates, mortality, falls, pneumonia associated with mechanical ventilation and length of hospital stay ${ }^{(17,24)}$.
Lack of professional development and valorization was related to job dissatisfaction and increase in the turnover of professionals, with consequent work overload and stress. According to a Brazilian study ${ }^{(25)}$, feeling insecure at work is a negative factor and is directly related to the quality of care provided. Institutions with unsatisfied professionals have higher turnover rates and occurrence of $A E$, such as medication errors and falls ${ }^{(25)}$. Tiredness and stress are human factors that contribute to the error, and it is the responsibility of the administration of the institution to create conditions so that these factors are not cause of professional error and do not reach the patient ${ }^{(25)}$. According to the theoretical framework adopted, these cultural factors can influence the sense or motivation of the individual in their everyday practices ${ }^{(14)}$.

In addition, to achieve Patient Safety, a proper organizational structure is required, with investment in personnel, equipment and materials. However, it is worth remembering that some practices, especially those for AE prevention, are not dependent on equipment and inputs, and can be developed with excellence by the professional team, in settings with scarce resources. As an example, nursing interventions in the area of risk prevention, since many care does not require the use of materials, but rather the commitment of all team members to develop and implement preventive care, interdisciplinary approach ${ }^{(26-27)}$.

In this sense, personal interactions can configure and reconfigure the practice ${ }^{(10-11,14)}$. This process can change the prescriptive aspect of the organization, something that must be recognized/ considered by the administration as a way to adapt the norms to the real characteristics of the organization and to obtain practices safer. It is a socially-constructed practice. It is an action that receives meaning or motivation from the individual inserted in a sociocultural context ${ }^{(10,14)}$, configuring a prescribed scope more compatible with the characteristics of work situations and, above all, of their specificities. In this way, the real would be closer to the prescribed one and would reach the PNSP's goals with safer practices, taking into account the real need of the patient. In order to transpose the prescribed scope to the institutional reality, some feedback actions were taken to the studied institution, such as presentation to the administration and the health team of the results found, in an attempt to contribute to the evaluation of health care conditions and reflection of strategies of process improvements.

\section{Study limitations}

The main limitations of the research are due to the methodology adopted, since case studies do not allow generalizations. The reality here does not necessarily represent the reality of other hospital institutions.

\section{Contributions to the fields of Nursing, Health or Public Policy}

This study contributes to nursing and advances in Patient Safety, insofar as it describes a distancing between what is prescribed in the Program and how it is implemented in the reality of the health services. The theoretical framework (Figure 1) was elaborated, based on the analysis of the results, to help in the understanding of how the practices written in the prescribed scope could be concretized in the reality of the organization. 


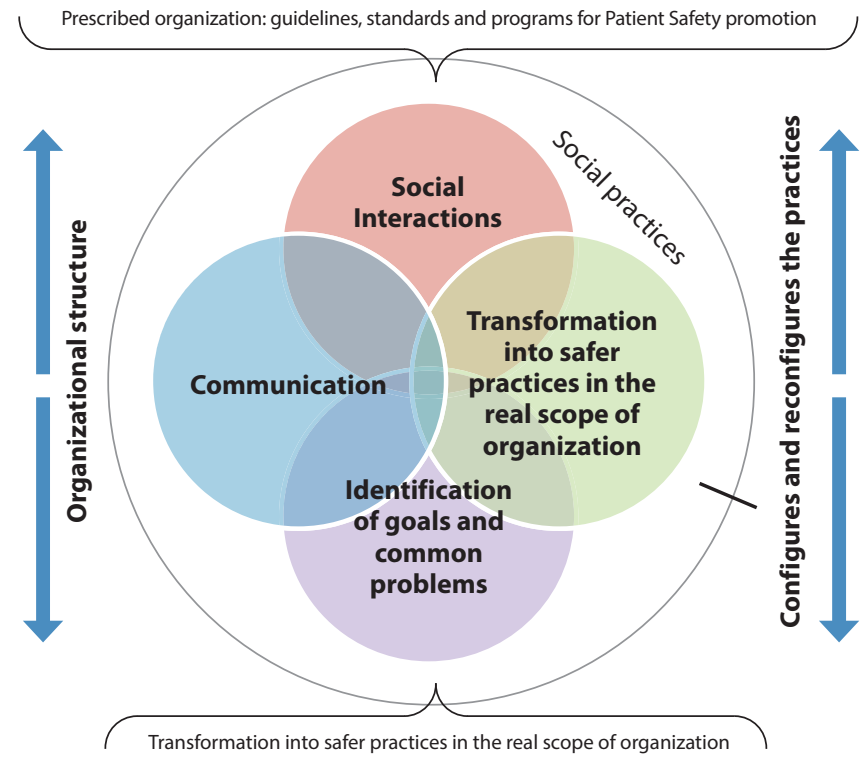

Figure 1- Safe practices: between the prescribed and the real

The analytical perspective adopted allowed identifying that the development of safe practices and the transition of an organization of high reliability depend on norms and guidelines (prescribed), of the environment with changes in the operational conditions. However, it mainly depends on intersubjectivity in health production, since it involves people, their interactions, communications and contextual influences, since the real is the informal, the dynamic being determined by social relations.

In the context of the study, there is a need to strengthen interactions between teams, NSP and management. Consequently, their actions, in which nurses and other leaders come in as protagonists in solving problems and developing strategies to achieve safer practices. And, also, investment in Permanent Education, ethical and political commitment, to build a social practice focused on Patient Safety. The study presents research gaps that need to be better studied, especially on the influence of the NSP at all hierarchical levels to achieve safer practices.

\section{FINAL CONSIDERATIONS}

Implementation of patient and PSP safety protocols was evidenced, mainly, in the prescriptive conception, with a distance between the prescribed one and the practices implemented in the real scope of the studied institution. Moreover, physical structure, inadequate facilities, lack of material resources, lack of quality of materials used and insufficient human resources are characterized as challenges to be overcome in order to achieve a safe practice in health care. Thus, challenges to safe practice involve difficulties of material and human resources, but mainly, it invades the transition from the prescriptive to the real.

\section{FUNDING}

This research was supported by the National Council for Scientific and Technological Development (CNPq - Conselho Nacional de Desenvolvimento Científico e Tecnológico), the Coordination for the Improvement of Higher Education Personnel (CAPES - Coordenação de Aperfeiçoamento de Pessoal de Nível Superior) and the Research Support Foundation of Minas Gerais State (FAPEMIG - Fundação de Amparo à Pesquisa do Estado de Minas Gerais).

\section{REFERENCES}

1. Siman AG, Cunha SGS, Brito MJM. Changes in management actions after the Hospital Accreditation. Rev Rene. 2016;17(2):165-75. doi: 10.15253/2175-6783.2016000200003

2. Andrade LEL, Lopes JM, Souza Filho MCM, Vieira Jr RF, Farias LPC, Santos CCM, et al. Cultura de segurança do paciente em três hospitais brasileiros com diferentes tipos de gestão Ciênc Saúde Coletiva. 2018;23(1):161-72. doi: 10.1590/1413-81232018231.24392015

3. Ministério da Saúde (BR). Agência Nacional de Vigilância Sanitária (ANVISA). Resolução da Diretoria Colegiada n. 36 , de 25 de julho de 2013. Institui ações para a segurança do paciente em serviços de saúde e dá outras providências [Internet]. Brasília; 2013 [cited 2018 Mar 21 ]. Available from: http://bvsms.saude.gov.br/bvs/saudelegis/anvisa/2013/rdc0036_25_07_2013.html.

4. Kohn LT, Corrigan JM, Donaldson MS, editors. To err is human. Washington (DC): National Academy Press; 2000.

5. Runciman W, Hibbert P, Thomson R, Van Der Schaaf T, Sherman H, Lewalle P. Towards an International Classification for Patient Safety: key concepts and terms. Int J Qual Health Care. 2009;21(1):18-26. doi: 10.1093/intqhc/mzn057

6. Mendes W, Pavão ALB, Martins M, Moura MLO, Travassos C. The feature of preventable adverse events in hospitals in the State of Rio de Janeiro, Brazil. Rev Assoc Med Bras. 2013;59(5):421-8. doi: 10.1016/j.ramb.2013.03.002

7. Sousa P, Uva AS, Serranheira F, Nunes C, Leite ES. Estimating the incidence of adverse events in Portuguese hospitals: a contribution to improving quality and patient safety. BMC Health Serv Res. 2014;14:311. doi: 10.1186/1472-6963-14-311

8. Jha AK, Plaizier NP, Larizgotia I. Patient safety research: an overview of the global evidence. Qual Saf Health Care. 2010;19(1):42-7. doi: 10.1136/qshc.2008.029165

9. Gama ZAS, Saturno-Hernández PJ, Ribeiro DNC, Freitas MR, Medeiros PJ, Batista AM, et al. Desenvolvimento e validação de indicadores de boas práticas de segurança do paciente: Projeto ISEP-Brasil. Cad Saúde Pública. 2016;32(9):e00026215. doi: 10.1590/0102-311X00026215

10. Chanlat JF. Ciências Sociais e Management. Rev Adm FEAD-Minas [Internet]. 2006[cited 2018 May 26];3(2):9-17. Available from: http:// revista.fead.br/index.php/adm/article/view/139/117 
11. Reed, M. Sociologia da gestão. Lisboa: Celta; 1997.

12. Alves M, Brito MJM, Rodrigues TRS, Araújo MT. O trabalho na prática de saúde. In: Salgado MI, Freire G, organizadores. Saúde e espiritualidade: uma nova visão da medicina. Belo Horizonte: Inede; 2013. p. 333-50.

13. Yin RK. Estudo de caso. Planejamento e métodos. 5a. ed. Porto Alegre: Bookman; 2015.

14. Weber M. Ensaios de sociologia. Rio de Janeiro: Zahar Editores; 1979.

15. Gondim SMG, Bendassolli PF. The use of the qualitative content analysis in psychology: a critical review. Psicol Estud. 2014;19(2):191-9. doi: 10.1590/1413-737220530002

16. Ministério da Saúde (BR). Portaria n. 529, de 1 de abril de 2013. Institui o Programa Nacional de Segurança do Paciente (PNSP) [Internet]. Diário Oficial da União, Brasília, 2 abr. 2013 [cited 2018 Jul 20]. Available from: http://bvsms.saude.gov.br/bvs/saudelegis/gm/2013/ prt0529_01_04_2013.html

17. Reis GAX, Hayakawa LY, Murassaki ACY, Matsuda LM, Gabriel CS, Oliveira MLF. Nurse manager perceptions of patient safety strategy implementation. Texto Contexto Enferm. 2017;26(2):e00340016. doi: 10.1590/0104-07072017000340016

18. Novaretti MCZ, Santos EV, Quitério LM, Daud-Gallotti RM. Nursing workload and occurrence of incidents and adverse events in ICU patients. Rev Bras Enferm. 2014;67(5):692-9. doi: 10.1590/0034-7167.2014670504

19. Ques AAM, Montoro CH, Gonzalez MG. Strengths and threats regarding the patient's safety: nursing professionals' opinion. Rev Latino-Am Enfermagem. 2010;18(3):339-45. doi: 10.1590/S0104-11692010000300007

20. Paranaguá TTB, Bezerra ALQ, Silva AEBC, Azevedo Filho FM. Prevalence of no harm incidents and adverse events in a surgical clinic. Acta Paul Enferm. 2013;26(3):256-62. doi: 10.1590/S0103-21002013000300009

21. Oliveira RM, Leitão IMTA, Silva LMS, Figueiredo SV, Sampaio RL, Gondim MM. Strategies for promoting patient safety: from the identification of the risks to the evidence-based practices. Esc Anna Nery. 2014;18(1):122-9. doi: 10.5935/1414-8145.20140018

22. Oliveira JLC, Gabriel CS, Fertonani HP, Matsuda LM. Management changes resulting from hospital accreditation. Rev Latino-Am Enfermagem. 2017;25:e2851. doi: 10.1590/1518-8345.1394.2851

23. Burström L, Letterstål A, Engström ML, Berglund A, Enlund $M$. The patient safety culture as perceived by staff at two different emergency departments before and after introducing a flow-oriented working model with team triage and lean principles: a repeated cross-sectional study. BMC Health Serv Res. 2014;14:296. doi: 10.1186/1472-6963-14-296

24. Möller G, Magalhães AMM. Bed baths: nursing staff workload and patient safety. Texto Contexto Enferm. 2015;24(4):1044-52. doi: 10.1590/0104-0707201500003110014

25. Rigobello MCG, Carvalho REFL, Cassiani SHB, Galon T, Capucho HC, Deus NN. The climate of patient safety: perception of nursing professionals. Acta Paul Enferm. 2012;25(5):728-35. doi: 10.1590/S0103-21002012000500013

26. Alves VC, Freitas WCJ, Ramos JS, Chagas SRG, Azevedo C, Mata LRF. Actions of the fall prevention protocol: mapping with the classification of nursing interventions. Rev Latino-Am Enfermagem. 2017;25:e2986. doi: 10.1590/1518-8345.2394.2986

27. Vasconcelos JMB, Caliri MHL. Nursing actions before and after a protocol for preventing pressure injury in intensive care. Esc Anna Nery. 2017;21(1):e20170001. doi: 10.5935/1414-8145.20170001 